\title{
ALINHAVOS ÀS LEITURAS DE UIRAN G. DA SILVA E HENRIQUE E. LIMA
}

A Reply to the Readings of Uiran G. da Silva and Henrique E. Lima

Jurandir Malerbaa

\section{DEBATE}

História da historiografia em perspectiva global 
$\mathbf{R}$ ecebo dos editores da revista Esboços: histórias em contextos globais dois artigos, "Outra história global é possível? Desocidentalizando a história da historiografia e a história antiga", de Uiran Gebara da Silva, professor da Universidade Federal Rural de Pernambuco (UFRPE), e "O global e seus paradoxos: a construção imaginada de um campo historiográfico", de Henrique Espada Lima Filho, professor da Universidade Federal de Santa Catarina (UFSC), aos quais, no espírito de debate da revista, eu deveria replicar, uma vez que ambos partem das leituras que fizeram do meu artigo "História da historiografia e perspectiva global: um diálogo possível?" (MALERBA, 2019), sobre potencialidades e limites da história global, pensados segundo experiências de pesquisa em história da historiografia.

Frustrarei editores e leitores, pois não vejo ser o caso aqui de replicar reflexões muito mais densas e frutíferas que o pretexto que as ensejou. Só me cabe agradecer aos editores pelo convite e aos professores Gebara da Silva e Espada Lima pelo que proporcionam em termos de reflexão teórica a mim e aos leitores de Esboços. Não obstante, permito-me uns poucos e breves comentários que me suscitaram as ricas leituras, sem qualquer pretensão de uma réplica no sentido pleno da palavra.

O artigo de Gebara da Silva (2019) faculta a leigos como eu uma achega de alto nível aos recentes desdobramentos da história antiga proporcionados pela perspectiva global. A despeito da diferença no que tange a especializações - Gebara da Silva é experto em História Antiga e conhece por dentro a história global, ao passo que eu proponho minha reflexão com base na história da historiografia feita naquela chave, mas sem ser dela um praticante -, parece-me que Gebara da Silva conseguiu retirar do meu texto muito mais do que ele potencialmente oferece. Em termos conceituais, reitera-se mais de uma vez em seu texto a formulação "história global da história da historiografia" - formulação que me soa um pouco redundante, pois acho que podemos ficar com "história global da historiografia", sem maiores perdas.

Uma pequena nuance de opinião emerge no início de seu texto, quando adverte que o caminho por mim escolhido gerou algumas "ratoeiras argumentativas", em especial no que respeita ao resgate que faço da perspectiva global na historiografia desde fins dos anos 1990, "dentro de uma armação narrativa que a enquadra numa sequência de 'modas historiográficas"', a tal ponto que meu escrito corre o risco de não levar a sério seu objeto (SILVA, 2019, p. 475). Nesse ponto, parece-me que escapou a Gebara da Silva a verve propositalmente irônica do meu texto.

Também não será despropositado entender que seu frontal senão à minha provocação da história global como sendo mais um modismo - não entendo que o seja, mas assim o enuncio, de maneira provocativa - não chega a ser confrontada por argumentos efetivos, mas lastreada num juízo de valor: o de que a história global, entre as modas, é das poucas que "de fato merecesse o adjetivo 'nova'" (SILVA, 2019, p. 475). Trata-se de uma questão de fé.

Nesse mesmo sentido, entendo, com ressalvas, a adjetivação de "nova história global" para se referir a esse movimento que vem dos anos 1990 em diante. Confesso minha impaciência com todas as bandeiras historiográficas e/ou teóricas que se anunciam sobre esse epíteto da novidade - a "nova história" ou a "nova nova história" -, com base na confrontação e na refutação de tudo que se fazia até então. Nada é realmente novo no conhecimento, se considerarmos as propriedades do abolir, do suspender, do superar, do preservar e do transcender incluídos no Aufhebung hegeliano. Nada é novo. Vamos percebendo cada vez mais claramente esse fato à medida que envelhecemos. 
Em “O global e seus paradoxos" (LIMA, 2019), as proposições de que a questão da exploração do potencial imaginativo, fundamental na criação de quaisquer histórias, lastreia também a consolidação da história global, e da participação de agentes outros que não apenas os especialistas na formulação dessas narrativas, são as grandes sacadas e contribuições da leitura de Henrique Espada Lima.

Reconheço fundamentadas as críticas dirigidas à obra de autores como Georg Iggers e Edward Wang. Pondero, porém, que os esforços de lggers - e outros, como Jörn Rüsen - de buscar superar as visões eurocêntricas em estudos interculturais desde os últimos anos do século XX e princípios do seguinte são evidências incontestes da insatisfação desses autores quanto à embocadura eurocêntrica da historiografia (e da história da historiografia) dominante mundo afora. Seu trabalho denota um esforço de superação, mas com certeza não é muito difícil apontar limites e problemas nessas tentativas, ainda que eu as considere incontestavelmente louváveis.

Lima oferece uma síntese crítica de enorme potência à extensão e à efetividade das chamadas epistemologias do Sul, dos estudos subalternos e pós-coloniais, que, em seu convite a "provincializar a Europa", reproduzem os mesmos protocolos que o mainstream intelectual ocidental. Compartilho integralmente dessa preocupação e do ponto de vista de Lima. Essa discussão é mais do que urgente num momento em que inúmeros profissionais da área de História, no Brasil, parecem ter encontrado, naquilo que lá fora se chama cultural studies, um lenitivo para todos os males e um substitutivo para os pecados da assim concebida velha, canhestra e eurocêntrica "teoria da história". Caberia aprofundar essa linha de reflexão, mas não aqui - e, definitivamente, não por mim. Permito-me reproduzir, por ser tão sugestivo, um parágrafo de Espada Lima (2019, p. 496):

Nas academias norte-americanas e europeias, os estudos subalternos e pós-coloniais se juntaram aos campos emergentes e críticos dos estudos de gênero e das relações raciais para configurar um novo quadro de reflexão sobre a realidade social que é fortemente marcado pela crítica à homogeneização e à adoção acrítica de categorias e teorias produzidas pelo "centro". A chamada a "provincializar a Europa" e a descentrar as formas de conhecimento "ocidentais" e seus "paradigmas racionalistas e normativos" em favor das "epistemologias do sul" desafia a ideia de que há categorias e formas de pensamento "universais". Essas mesmas teorias críticas ganham força e visibilidade, entretanto, ao reverberarem em escala transnacional por meio das mesmas caixas de ressonância intelectual que haviam consagrado os maitres-à-penser europeus, igualmente inovadores e iconoclastas décadas antes. A historiografia em chave "global" segue rigorosamente os mesmos caminhos de difusão e afirmação, e passa a enveredar-se por todos os lugares do "sul global" seguindo um padrão notavelmente homogêneo.

Isso me leva de volta ao texto de Gerbara da Silva (2019, p. 478), quando evoca o "impacto gradual da crítica pós-colonial", de fora, por meio da obra de Edward Said e Martin Bernal, e de dentro, por meio do trabalho de uma série de outros autores. Mais uma vez ironizando e provocando, pergunto o que é dentro e fora, onde é o West e onde é o The Rest. Said é palestino-americano, cidadão americano, e Bernal 
é um acadêmico britânico - os dois estão tão "de dentro" da cultura ocidental como os demais mencionados por Gerbara da Silva: Mattingly, Alcock, Whittaker, Webster, Le Roux, Hingley ou Bowersock.

Em outras palavras, quão fora do mainstream acadêmico ocidental estão autores como Dipesh Chakrabarty, que guarda posição de prestígio como Lawrence A. Kimpton Distinguished Service Professor in History na Universidade de Chicago e que publicou, em inglês, pela editora da Universidade de Princeton sua obra mais conspícua, na qual propõe "provincializar a Europa"? Acho difícil conceber como "de fora" os luminares da crítica "pós-colonial". Mas não caberia aprofundar esse tema aqui.

Por fim, reitero minha gratidão à editoria da Esboços pela distinção do convite e aos professores Uiran Gebara da Silva e Henrique Espada Lima por suas leituras generosas.

\section{REFERÊNCIAS}

LIMA, Henrique Espada. O global e seus paradoxos: a construção imaginada de um campo historiográfico. Esboços, Florianópolis, v. 26, n. 43, p. 486-500, set./dez. 2019

MALERBA, Jurandir. História da historiografia e perspectiva global: um diálogo possível? Esboços, Florianópolis, v. 26, n. 43, p. 457-472, set./dez. 2019.

SILVA, Uiran Gebara da. Outra história global é possível? Desocidentalizando a história da historiografia e a história antiga. Esboços, Florianópolis, v. 26, n. 43, p. 473-485, set./dez. 2019.

\section{NOTAS}

\section{AUTORIA}

Jurandir Malerba: Doutor. Professor titular, Universidade Federal do Rio Grande do Sul, Instituto de Filosofia e Ciências Humanas, Departamento de História, Porto Alegre, RS, Brasil.

\section{ENDEREÇO PARA CORRESPONDÊNCIA}

UFRGS/IFCH, Departamento de História, Av. Bento Gonçalves, 9500, Agronomia, 91509-900, Porto Alegre, RS, Brasil.

\section{FINANCIAMENTO}

Esta réplica foi financiada com bolsa de Produtividade em Pesquisa do Conselho Nacional de Desenvolvimento Científico e Tecnológico (CNPq).

\section{APROVAÇÃO DE COMITÊ DE ÉTICA EM PESQUISA}

Não se aplica.

\section{CONFLITO DE INTERESSES}

Não houve conflito de interesses.

\section{LICENÇA DE USO}

Este artigo está licenciado sob a Licença Creative Commons CC-BY. Com essa licença você pode compartilhar, adaptar, criar para qualquer fim, desde que atribua a autoria da obra. 


\section{PUBLISHER}

Universidade Federal de Santa Catarina. Programa de Pós-Graduação em História. Portal de Periódicos UFSC. As ideias expressadas neste artigo são de responsabilidade de seus autores, não representando, necessariamente, a opinião dos editores ou da universidade.

\section{EDITORES}

Alex Degan

Beatriz Mamigonian

Fábio Augusto Morales

Flávia Florentino Varella (Editora-chefe)

Tiago Kramer de Oliveira

Waldomiro Lourenço da Silva Júnior

Como citar: MALERBA, Jurandir. Alinhavos às leituras de Uiran G. da Silva e Henrique E. Lima. Esboços, Florianópolis, v. 26, n. 43, p. 501-505, set./dez. 2019. 